\title{
Implementing Scaled-Agile Frameworks at Non-Digital Born Companies - A Multiple Case Study
}

\author{
Florian Schuch \\ Goethe Business School, \\ Germany \\ florian.schuch@gmx.net
}

\author{
Daniel Gerster \\ University of St. Gallen, \\ Switzerland \\ daniel.gerster@student.unisg.ch
}

\author{
Daniel Hein \\ University of Bamberg, \\ Germany \\ daniel.hein@uni-bamberg.de
}

\author{
Alexander Benlian, \\ TU Darmstadt, \\ Germany \\ benlian@ise.tu-darmstadt.de
}

\begin{abstract}
For traditional enterprises to harness the advantages of organizational agility, scaled-agile frameworks seem to be more appropriate to adopt agile practices at large scale. However, the adoption of agile practices often creates trade-offs between the implementation of an ideal theoretical framework and company-specific necessities. While extant research has covered the implications and challenges when adopting agile structures, our research focuses on the how and why of such trade-offs using Socio-Technical Systems Theory. Drawing on the results of an exploratory multiple case study, we reveal that companies either choose a top-down or bottom-up approach for implementation. While the first often is triggered by the need to increase customer centricity, the latter is mostly triggered by the need to increase the number of releases. Moreover, we found that the selected implementation approach has significant impact on the key design parameters for and the content of the implementation of scaled-agile frameworks.
\end{abstract}

\section{Introduction}

The current business environment in the digital age can be characterized by high volatility and uncertainty that, contrary to known risks, is hard to manage with standard processes [1]. As the absence of routine has become the new normal in today's hypercompetitive markets, capabilities to address these challenges resulting from digital transformation have gained significant importance [1]. This ability to sense and effectively address unforeseen developments is termed 'organizational agility' [2]. Enterprises, regardless of industry, size or age, implement agile practices to become more responsive to highly volatile markets [3].

The organizational change that goes along with the agile transformation process is guided through the implementation of agile structures through scaled-agile frameworks and the corresponding cultural change [4].
From a theoretical point of view, the implementation of new work systems and the induced organizational change has been described using the Socio-Technical Systems-Theory (STS) by Bostrom and Heinen $[5,6]$. However, this description of an organizational change process operates with various generic factors requiring adjustment to the context of scaled-agile frameworks. This is even more true when the applied methods to coordinate behavior inside IT become "scaled" to include members of different functions and divisions. This is potentially the case at scaled-agile frameworks which are striving to extend agility beyond software development [7].

Previous research has dealt with the implications of the adoption of agile structures in non-digital born enterprises for the organizational design, including challenges and success factors when implementing agile methods [3, 8, 9]. Non-digital born enterprises encompass companies that do not have digital technologies at the core of their business model [10]. Also, the process by which scaled-agile frameworks are implemented within those type of enterprises itself has been investigated recently [8]. However, these works either emphasize the roles of specific framework templates (i.e. LeSS and SAFe) and choose a theoryagnostic approach to analysis or they do not pertain to scaled-agile frameworks implemented in the entire organization. Consequently, our research seeks to address this gap by providing insights on (1) the design parameters for an enterprise-wide and scaled-agile framework agnostic implementation and (2) the choices that pertain to the content of the implementation from a socio-technical perspective.

Thus, this paper outlines idiosyncrasies of scaledagile framework implementation in non-digital born companies based on an exploratory multiple case study. Specifically, we aim at addressing the following research questions which, in their order, reflect the STS implementation approach:

1. What are the key design parameters for scaledagile framework implementations in nondigital born enterprises? 
2. What design patterns for the implemented content of scaled-agile frameworks can be identified?

We describe our findings based on a qualitative research approach that includes six global cases of nondigital born companies across different industries.

\section{Background}

This chapter introduces the relevant core concepts. First, we describe the origin of agility-concepts and their impact on the organizational design. We then introduce scaled-agile frameworks by providing a generic template of its constituting elements. We conclude with a brief introduction of socio-technical system theory as our theoretical lens.

\subsection{Agility and Organizational Agility}

This section clarifies the term agility as it bears ambiguity due to its context-dependent meaning [11].

On one hand, in the context of agile manufacturing, agility can be described as a property of operational processes and is directed at improving their speed and quality of output [12]. In the context of software development, the aim of agile development is achieved by realization of various principles that were first codified in the Agile Manifesto by Fowler and Highsmith (2001), but that can be traced back to the principles of "leanness" and "flexibility", with leanness meaning the maximization of simplicity and quality and with flexibility focusing on the continual readiness to embrace change [11].

On the other hand, ambiguity emerges from the fact that agility has emancipated itself from its operational roots (e.g. workforce agility, supply chain agility, etc.) and migrated to the larger context of the firm - then being referred to as organizational agility. For this term, a variety of conceptualizations exist that include different numbers and kinds of reflective subdimensions and that are linked to the literature on dynamic capabilities [2]. As such, it places discrete activities into the context of a strategic firm capability for competing in an unstable business environment [11]. In the context of enterprise-wide adoption, organizational agility is referred to the term enterprise agility emphasizing the enabling role of IT [14].

We proceed with the definition of agility as "the continual readiness of an entity to rapidly or inherently, proactively or reactively, embrace change, through high quality, simplistic, economical components and relationships with its environment" [11]. We view scaled-agile frameworks as an option to achieve those desired capabilities.

\subsection{Scaled-Agile Frameworks}

This chapter introduces scaled-agile frameworks to transform an entire organization. Scaled-agile frameworks are sets of rules on how to establish an organization such that it reflects the values that are associated with an agile approach [15]. These values represent developers' experiential understanding favoring parsimony, pragmatism, frequent iterations and regular communication. Information system development methods that incorporate these values and that are predecessor to scaled-agile frameworks are eXtreme Programming (XP) [16], Lean Software Development (LSD) [17] and Scrum [18]. However, these were used at the team level only to improve the process of information system development [19], providing no answer on how to coordinate larger groups of developers.

These methods can be used to coordinate work across teams to "scale agile" $[5,9]$ with especially Scrum as a method exerting influence on the design of agile frameworks. Thus, scaled-agile frameworks are codified descriptions of structure and process for organizations that strive to remain fast in delivery and responsive to market dynamics despite a growing number of participants and the detrimental effects that go along with increased communication efforts.

We continue with describing the structures of scaled-agile frameworks following Kniberg (2012) who revealed agile practices and structures as applied by Spotify. According to the Spotify model, agile units can be defined to be made up of five to nine members that are organized to form an agile development team with a product owner. A scaled-agile structure uses this blueprint to create several teams which are termed "squads" with individual product owners into a multiproduct structure. For highly complex products that require a break-down into several components, scaled-agile structures coordinate more than six squads respectively 50 people that each possess their own product feature owner that in turn coordinates the individual development teams [21]. Product feature owners report to a tribe lead that supervises progress for each aspect of the product [3].

However, terminology and the level of detail of the structures of scaled-agile frameworks differs substantially across established frameworks, for which we refer to the work of Kalenda et al. (2018).

\subsection{Socio-Technical System Theory}

We chose the socio-technical systems theory approach as theoretical lens for investigation. STS can 
be traced back to the works of Leavitt [22] and Bostrom and Heinen $[5,6]$ and explicitly considers the interaction between variables in a work system before, during, and after the introduction of new information systems. The STS approach has found wide adoption to describe several phenomena requiring consideration of social and technical aspects [23, 24, 25]. Most recently, STS also found successful adoption in the context of the adoption of agile practices [e.g. 5,10$]$.

STS considers the interaction between variables of the social technical work system. The social system consists of actors including people with their culture and abilities and structure mainly related to the organizational or project structures [22]. The technical system consists of tasks including subtasks which are required for the production of goods and services and technology including tools which are required to fulfil the work $[6,22]$.

According to STS, organizational change induced by the implementation of new information systems takes place in a three-stage approach: (1) the strategic design process, (2) the socio-technical system design process and (3) an ongoing management process [6]. The first stage defines goals and responsibilities for the project explicitly. In the second stage, the new social and technical work system is designed, while the third stage is an iteration between monitoring the implemented system and the holistic adjustment along the dimensions postulated by STS [6]. We proceed to apply STS to systemically describe the process of framework implementation as well as the work system design to analyze how the scaled-agile frameworks are implemented within the different dimensions. Our research approach is described in more detail in the following chapter.

\section{Research Method}

We chose an exploratory multiple case study as our research design following the phenomenological approach of qualitative research [26]. The underlying study relies on a non-random purposive sampling technique that included dedicated individuals who were playing an actual role in the design and implementation of scaled-agile frameworks at their organization and at different levels, such as tribe leads, product owners, or scrum masters [27]. The selection criteria for case companies were that they were not born digital and they had to show first implementations of scaled-agile structures. Table 1 provides details on the six case study companies and conducted interviews. We have selected this approach, as we find a lack of empirical observations regarding our research questions, favoring a deep rather than a generalizable understanding of the phenomenon in question. Thus, our expert sampling approach was driven by a need for theoretical saturation [27].

In total, 18 semi-structured interviews were conducted that lasted from thirty-two to sixty minutes and that were led in a discovery-oriented way following a preset interview guideline following the recommendations on in-depth interviews [28].

The initial interview guideline was developed adapting the phenomena mentioned in the stages of the STS approach to the context of scaled-agile frameworks. Hence, the interview guideline consisted of questions on the strategic design parameters and the implemented content of scaled-agile frameworks. The guideline was refined progressively with additional and more focused questions to clarify any thematic differences. Except for one interview, all others were conducted face-to-face. All interviews were audiorecorded. The recordings were immediately transcribed verbatim to encourage theoretical sampling and the coding procedure, resulting in 180 pages of verbatim transcript.

The coding procedure purposefully consisted of open, axial and selective coding to reflect theory while simultaneously allowing its potential expansion [29]. The authors checked the transcripts for completeness

Table 1. Overview and specifics of case study companies and conducted interviews

\begin{tabular}{|l|l|l|l|l|l|l|l|}
\hline Case ID & Industry & $\begin{array}{l}\text { Head- } \\
\text { quarter }\end{array}$ & Size $^{\mathbf{1}}$ & $\begin{array}{l}\text { Company } \\
\text { Age [years] }\end{array}$ & $\begin{array}{l}\text { Depart- } \\
\text { ment }\end{array}$ & $\begin{array}{l}\text { Inter- } \\
\text { views [\#] }\end{array}$ & $\begin{array}{l}\text { Interviewees' } \\
\text { Position }\end{array}$ \\
\hline AirCo & Aviation & Germany & $120+$ & $60+$ & Business & 2 & $(1) ;(3)$ \\
\hline FinCo & FinCo & Netherlands & $50+$ & $20+$ & Business & 3 & $(1) ;(2) ;(3)$ \\
\hline CarCo & Automotive & Germany & $100+$ & $100+$ & Business & 3 & $(1) ;(2) ;(3)$ \\
\hline PubCo & Media & Germany & 1 & $70+$ & Business & 2 & $(2) ;(2)$ \\
\hline RealCo & Real Estate & Germany & 1 & $10+$ & Business & 3 & $(1) ;(2) ;(2)$ \\
\hline TelCo & Telecommunication & Germany & $200+$ & $60+$ & Business & 5 & $\begin{array}{l}(1) ;(2) ;(3) ;(3) \\
(3)(3)\end{array}$ \\
\hline
\end{tabular}

1) in '000 [employees]

2) (1) Senior Management Level (e.g. Tribe Lead); (2) Management Level (e.g. Product Owner); (3) Team Member Level (e.g. Scrum Master). 
and analyzed them separately from one another. Where available, memos or notes were used to capture ideas, further questions or thematic differences. The qualitative data analysis software MaxQDA supported the coding procedure, facilitating comparison of the coding results and memos as well as checking for sufficient inter-coder reliability. Where interpretations between coders diverged, perspectives were discussed iteratively to reach a consensus. This was done to ensure consistency of coding and interpretation. Application of the constant comparative method [29] ensured that new data incidents that emerged from later interviews were related to the incidents that occurred in previous interviews, leading to either their assignment to existing concepts, or create new concepts or categories.

\section{Results}

Based on the interviews and the induced case study findings, we present the results of applying STS to the implementation of scaled-agile frameworks, the definition of design parameters for the implementation, and the choice of content for implementation in the dimensions of the work system.

\subsection{Socio-Technical Work System and Implementation Design}

Figure 1 presents the work system design for scaledagile frameworks with the different elements of those frameworks either assigned to the social or the technological work system.

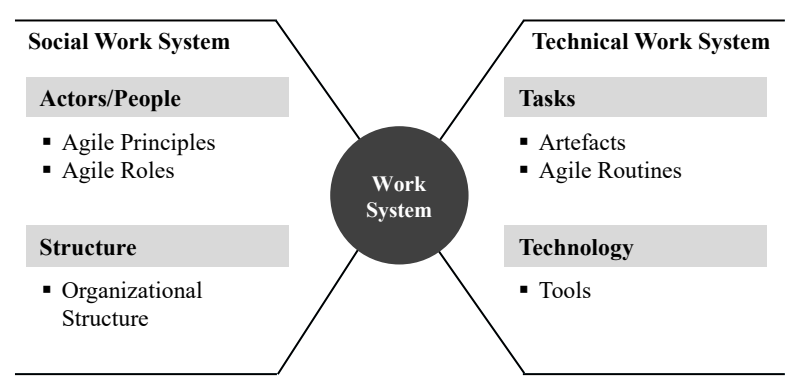

Figure 1. Socio-Technical Work System Design for Scaled-Agile Frameworks

As described in chapter 2.3, the social work system consists of actors or people with their culture and abilities and the organizational structure. In the context of scaled-agile frameworks, people with their culture and abilities are related to the agile roles and principles within those frameworks. The structure variable is related to the organizational structure driven by the tribe or multi-team and squad or team definition. Whereas we fully cover the social work system in this research, we exclude artefacts as technical work system element with subordinate relevance from our analysis. The technical system consists of tasks including subtasks which are required for the production of goods and services and technology including tools which are required to fulfil the work. The task variable consists of artefacts and agile routines which are required to create the product or service. Artefacts consist of the product and sprint backlog. Agile routines consist of all ceremonies and meetings to align on current and future activities. The technology variable encompasses all tools which support the agile way working induced by the implementation of scaled-agile frameworks.

While the STS implementation approach comprises three phases, we observed that when implementing scaled-agile frameworks, companies combine phase two and three of the STS approach to an iterative process where design and implementation activities alternate continuously.

\subsection{Design Parameters for Scaled-Agile Framework Implementation (STS Phase 1)}

In the first phase of the STS approach, the design parameters of the scaled-agile framework implementation are defined. The design parameters cover the definition of objectives to pursue with the implementation, the definition of the implementation scope, the definition of the implementation ownership, an analysis of the organizational environment and the creation of an implementation and diffusion approach. In the following, we describe how our case companies made their decisions in terms of the design parameters when implementing scaled-agile frameworks.

The case companies pursued different objectives during the implementation of the scaled-agile frameworks. In most cases, increasing delivery speed and shorter time-to-market is the major objective for implementing scaled-agile frameworks (AirCo, RealCo, PubCo, TelCo). Moreover, respondents of FinCo and CarCo stated the increase of customer centricity as the fundamental objectives to be achieved by creating products that better satisfy existing, changing, and emerging customer needs as well as the reduction of organizational complexity by introducing end-to-end responsibility and abolishing old management structures, such as silos. Respondents from all case companies added as objective the attraction of young talents by having an agile, less hierarchical and more flexible working environment.

The implementation scope for scaled-agile frameworks varied from single initiatives in different units, transformations of individual parts of an unit, the redesign of an entire unit or a company-wide implementation. In the case companies which chose an 
unit- or enterprise-wide implementation scope, the implementation itself was part of an entire agile transformation program (CarCo, FinCo).

The implementation ownership lies in a dedicated department or team named 'implementation squad' inside the unit or company (AirCo, CarCo, FinCo, TelCo). Their size and constitution varied with the organizational scope of the implementation. However, each squad consists of the implementation or transformation lead, all agile coaches, and scrum masters at minimum. At CarCo and FinCo the transformation lead directly reported to the department head or $\mathrm{CEO}$

The organizational environment of implementation is empirically characterized by the corporate terminology and the understanding by everyone in the organization, the prevalent operating mode regarding time horizons and work focus, the degree of motivation by the participants and the regulatory environment.

All case companies chose a stepwise and iterative implementation approach, as interviewees emphasized the limited feasibility for a big bang-adoption and the desire to reduce implementation risks. Hence, all case companies started with a constituent part of the entire implementation scope and then continued with additional parts or teams. Whenever the initial implementation of one team or unit was setup, CarCo and FinCo started to iteratively improve the initial design with the teams following a continuous improvement approach. We observed that the implementation approaches can be differentiated by their diffusion direction (i.e. top-down or bottom-up). A top-down approach starts with the definition of the overall product structure and the corresponding product features (CarCo, FinCo). A bottom-up approach initiated few scrum teams before starting to implement required structures to organize several agile teams. CarCo and FinCo had a fixed timeline for implementation that progresses in waves and finishes the transition within approximately 18 months. AirCo, RealCo, PubCo and TelCo followed a demand-driven approach transforming volunteering teams or units.

\subsection{Scaled-Agile Framework Work System Design (STS Phase 2 and 3)}

In the second phase of the STS approach, the social and technical work system is designed considering the defined design parameters for the scaled-agile framework implementation. The description of work system design follows the illustration shown in figure 1. In the following, we present our results reflecting the implementation content.

The key agile principles within the people element of the social work system are transparency, continuous improvement, result ownership, and customer centricity. [16] Transparency shall be achieved on the contribution of single tasks and products to the company or unit goals, on the interdependencies between squads, product features or tribes (CarCo, FinCo), and current problems causing potential delays on product increment delivery or the implementation of the scaled-agile framework itself (AirCo, RealCo, PubCo, TelCo). Continuous improvement is related to products, internal processes and structures and is achieved by involving customer feedback early and repeatedly into both the product development and service execution. For internal processes or structure, continuous improvement is achieved via regular and structured meetings that allow reflection on success stories and improvement areas (AirCo, TelCo). All case companies mentioned that establishing a more positive failure culture was crucial for successful adoption, as only the root cause analysis allowed extraction of learnings. We found that result ownership plays an important role in the transformation from a task orientation to outcome orientation, as interviewees from CarCo and FinCo underlined the significance that lay in the shift of ownership from individuals to groups or management teams. This collectivization of ownership prevents the rise of a blame culture, as responsibility is shared equally among members. This relocation of ownership worked only when either management or product owner were confident and trusted the team to make the right decisions (CarCo, FinCo, TelCo). Customer centricity and customer value were aimed for to be at the core of every activity throughout the entire company. CarCo and FinCo explicitly stated that the focus of all activity is the paying customer rather than an internal one, ultimately stopping any project that fails to explain its contribution to customer value.

The organizational structure is divided in a multiteam and team structure. In general, scaled-agile frameworks introduce a matrix structure that has a product-orientation on the vertical and a professional or technical focus on the horizontal axis (AirCo, FinCo, CarCo, TelCo). Figure 2 builds on the generic agile unit described by Kniberg (2012) and extends it by the notion of a scaled-agile unit.

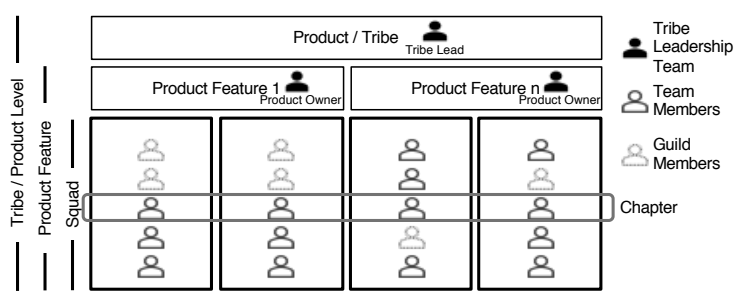

Figure 2. Generic Scaled-Agile Unit based on Kniberg (2012) 
The products on the first level of the vertical dimension are in contact with external customers, delivering customer value. Each tribe has end-to-end responsibility for delivering the product to the market, profit and loss accountability, and dispose their budget based on the product owner's prioritization. (CarCo, FinCo, TelCo). We observed that the structure below tribe level strongly depended on the implementation scope of the scaled-agile framework adoption. Whereas in smaller implementations, the product owner directly governs the individual squads that create product increments or features, for larger ones the level of product owner is followed by a level of product features which then subdivides into the different squads. Each product feature has a product owner, thus terming the role "product owner" on tribe level the "tribe lead" (CarCo, FinCo, TelCo).

On the horizontal dimension, "chapters" or "guilds" pervade the organizational structure, unifying professional skills or topics, such as UX design, data management, or customer experience. Guilds as informal bodies consist of employees who work in the same area of expertise, topic, have the same interest, discuss current problems or best practices as well as set standards for future development. Chapters, by contrast, are formal bodies that permeate the horizontal structure and contain relationships of disciplinary assignment. The informal and non-disciplinary character are explicitly stated as advantages of the guild approach as guilds can disseminate information across the organization at specific, given occasions. However, this occasion-driven and informal character prevents them from practicing discussion as "raison d'être" when there is no actual need to do so (CarCo, FinCo).

All case companies designed their teams with endto-end-responsibility as interdisciplinary and crossfunctional. Special focus was placed on breaching the division between IT and business units. Furthermore, we observed that the required skill set strongly depends on the desired outcome, but that the respective experts were grouped along industry specific knowledge (e.g. customer journey experts, technical experts) and IT knowledge (e.g. developer, tester, UX designer). Interviewees from AirCo, TelCo, CarCo and FinCo stated that the target state of an agile team was a homogenous set of experienced employees with a broad variety of skills. In fact, within agile teams it is proactively avoided to have deep specialist or luminaries focusing on one knowledge area only as those employees will become bottlenecks.

Each scaled-agile framework describes different roles on team and multi-team level with the number of roles varying among the frameworks. As described, the basic team roles are the product owner, scrum master, agile coach and the required squad member which are implemented in most case companies (AirCo, CarCo, FinCo, RealCo, TelCo).

We observed that the degree of implemented multiteam roles varied across the case companies. We found that on multi-team level the additional roles are a tribe lead, product owners of the product features, chapter leads, and guild leads. Two case companies (AirCo, TelCo) introduced release train engineers, business owners, and product managers. The release train engineer's responsibility is to manage frequent releases when working with more than one squad at the same release, whereas the latter supporting the product owners during planning and releasing. However, both case companies mentioned that the last two roles were contradicting the idea of end-to-end responsibility of one product owner and were thinking about removing the roles. Moreover, FinCo, CarCo, and TelCo pointed out that the introduction of new roles must be handled carefully and centrally, as people tend to introduce new roles to get back to their old structure and areas of responsibility. Especially in case companies that had chosen SAFe, it was mentioned that each role provided by the framework is critically analyzed for its purpose and its compliance with the implementation objectives.

In general, agile routines provide transparency on the current progress, next steps and potential impediments along the product development process. However, the number, type, and degree of implementation on multi-team level varied among the case companies. On multi-team level CarCo and FinCo made a retrospective and a standup meeting mandatory on regular, at least biweekly basis. Moreover, both case companies especially focused on the planning and review meetings. Both companies followed a two-step planning approach, where the first sprint planning covers the alignment on tribe leadership level and where the prioritization and dependencies in the upcoming sprint are discussed. Furthermore, interviewees from FinCo, $\mathrm{CarCo}$, and TelCo outlined that planning beyond the time scope of the next sprint was essential to retain an overview of the product roadmap. Different methods are used among our case companies to plan beyond the next sprint, also varying on the period scope. AirCo und TelCo are using a so-called Program Increment Planning (PIP). PIP focuses on managing software releases within IT-focused projects and covers a time period between eight to twelve weeks. FinCo and CarCo are using Quarterly Business Reviews (QBRs) to plan on product planning ahead for three months. Within the QBR meetings, participants align the product goals for the next three months, discuss implications and respective objectives on product feature level, and align dependencies in terms of deliveries or skills. Sprint reviews on multi-team level are also executed differently among the case companies. Whereas FinCo 
and CarCo explicitly state that overall sprint reviews are key to inform all teams on the progress and therefore are to be conducted after each sprint, others conduct overall reviews only if major progress has been reached.

Chapter, guilds, and all hands meetings are used for multi-team alignment. Chapter and guild meetings are used to align best practices and to set standards within the respective focus topic of the chapter or guild it was founded for. All hands meetings are used to share updates to the whole tribe, mostly taking place every three to four weeks.

When implementing scaled-agile frameworks, the technology variable of the work system encompasses tools which support the agile way of working. Generally, agile working tools are either physical or technical. Physical tools include boards, walls (e.g. white board walls), rooms or collaboration areas to visualize and provide transparency on the current progress, next steps, and other topics. Technical tools are software tools such as JIRA, Trello or Confluence, with the latter being a web-based knowledge management system comparable with a company's internal Wikipedia. (AirCo, CarCo, FinCo, PubCo, TelCo). Physical tools do not require training and are therefore easier to use. In non-co-located teams, physical boards lack location independence. All case companies stated that physical tools foster motivation and task commitment. Besides the advantage of being location-independent, most case companies stated that technical tools provide better view on the big picture across teams and sprints. Interviewees from CarCo and FinCo mentioned that technical tools are contradicting the idea of fostering communication within and beyond the teams, as they make it possible to assign tasks to someone without talking to the person.

\section{Discussion}

Our results show that companies either follow a topdown (CarCo, FinCo) or bottom-up (AirCo, PubCo, RealCo, TelCo) approach when implementing scaledagile frameworks. When following a top-down approach, companies define the product structure at the top first before initiating the first squads. Contrary, companies following a bottom-up approach initiate agile teams first and implement multi-team structures subsequently. Moreover, we found that the followed approach has a significant impact on the definition of the implementation design parameters (STS Phase 1) as well as the choices that pertain to the content of the implementation (STS Phase 2 and 3). Table 2 summarizes the results of our case study.

In the context of the definition of the implementation design parameters, the chosen approach has an impact on the pursued objective, the implementation scope and ownership as well as on the implementation and diffusion approach. Our results show a relationship between the approach that is chosen and the ultimate objective that is pursued, as case study companies with the primary objectives of reducing organizational complexity and increasing customer centricity choose a top-down approach, whereas companies who aim at increased delivery speed and reduced time-to-market implement a bottom-up approach. Regarding the implementation scope, our results reveal that companies following a top-down approach choose a wider implementation scope (e.g. unit- or company-wide implementation) as companies following a bottom-up approach. CarCo and FinCo either implemented the scaled-agile framework on company or unit level, whereas AirCo, PubCo, RealCo and TelCo transformed multiple teams or parts of an unit. Moreover, we found that all case companies are using an implementation squad that has the ownership over the implementation. But, in contrast to companies following a bottom-up approach, top-down case companies embedded the implementation squad with a direct report to the unit head or CEO to facilitate management approval for decision and resources. Among all case companies, either following a bottom-up or top-down approach, we observed three fundamental tasks of implementation squads: (1) design and continuous improvement of the scaled-agile framework, (2) the orchestration and support of the organizational and cultural change, and (3) creation of organizational structures which support an agile way of working. In terms of the chosen implementation and diffusion approach, we found that case study companies following a top-down approach started the implementation by defining the overall product and product feature structure including the corresponding tribes and squads. Throughout the implementation, the initial product and product feature structure is continuously improved by adjusting the tribe and squad structure. Furthermore, those case companies with a top-down approach have a fixed timeline for implementation that progresses in waves and finishes the transition within approximately 12 to 18 months. In contrast, companies with a bottom-up approach had no finite timeline for the implementation. Beside the definition of the fundamental design parameters, the subsequent choices that pertain to the content of the implementation also depend on the chosen implementation approach.

In the context of agile principles, companies following a top-down approach defined transparency on the contribution of tasks to the company or unit goals, result ownership through the collectivization of responsibility and customer centricity as the key principles. In contrast, those companies following a 
Table 2. Observed scaled-agile implementation approaches

\begin{tabular}{|c|c|c|}
\hline & Top-Down Implementation & Bottom-Up Implementation \\
\hline Cases & CarCo, FinCo & AirCo, PubCo, RealCo, TelCo \\
\hline \multicolumn{3}{|c|}{ 1. Design Parameters for Scaled-Agile Framework Implementations } \\
\hline 1.1 Implementation Objectives & $\begin{array}{l}\text { - Increase Customer Centricity } \\
\text { - Reduce organizational complexity }\end{array}$ & $\begin{array}{l}\text { - } \text { Increase delivery speed } \\
\text { - Shorten time-to-market }\end{array}$ \\
\hline 1.2 Scope & $\begin{array}{ll}\text { - } & \text { Entire unit } \\
\text { - } & \text { Company-wide implementation }\end{array}$ & $\begin{array}{l}\text { - Single teams } \\
\text { - Parts of an unit }\end{array}$ \\
\hline 1.3 Ownership & $\begin{array}{l}\text { - Unit or department head } \\
\text { - CEO }\end{array}$ & $\begin{array}{ll}\text { - } & \text { Team lead } \\
\text { - } & \text { Multi-team lead } \\
\end{array}$ \\
\hline $\begin{array}{l}1.4 \text { Implementation and } \\
\text { diffusion }\end{array}$ & $\begin{array}{l}\text { - Time-boxed wave approach } \\
\text { (approx. } 18 \text { month) }\end{array}$ & $\begin{array}{l}\text { - Demand-driven approach } \\
\text { - Not time-boxed }\end{array}$ \\
\hline \multicolumn{3}{|c|}{ 2. Scaled-Agile Framework Work System Design } \\
\hline 2.1 Agile Principles & $\begin{array}{l}\text { Transparency on contribution of } \\
\text { single tasks and dependencies } \\
\text { between squads, features or tribes } \\
\text { - Continuous improvement for } \\
\text { product, processes and structure } \\
\text { - Result ownership through } \\
\text { collectivization of responsibility }\end{array}$ & $\begin{array}{l}\text { - Transparency on current problems } \\
\text { causing potential delays } \\
\text { - Continuous improvement mainly } \\
\text { for internal processes to mitigate } \\
\text { future potential delays }\end{array}$ \\
\hline 2.2 Organizational Structure & $\begin{array}{l}\text { Focus on multi-team structure } \\
\text { introducing a matrix structure with } \\
\text { product-orientation on the vertical } \\
\text { and a professional or technical } \\
\text { focus on the horizontal axis }\end{array}$ & $\begin{array}{l}\text { - Focus on team structure and } \\
\text { configuration creating an agile team } \\
\text { with a homogenous set of } \\
\text { experienced employees with a } \\
\text { broad variety of skills }\end{array}$ \\
\hline 2.3 Agile Roles & $\begin{array}{l}\text { Focus on roles on multi-team level } \\
\text { first before introducing roles on } \\
\text { team level }\end{array}$ & $\begin{array}{l}\text { - Focus on introducing roles on team } \\
\text { level first, adding roles on multi- } \\
\text { team level when required } \\
\text { - Roles on multi-team level focus } \\
\text { coordination to increase speed }\end{array}$ \\
\hline 2.4 Agile Routines & $\begin{array}{l}\text { - Focus on agile routines that foster } \\
\text { multi-team alignment } \\
\text { - Using routines such as quarterly } \\
\text { business reviews for product } \\
\text { planning }\end{array}$ & $\begin{array}{l}\text { - Focus on agile routines fostering } \\
\text { team alignment, adding routines on } \\
\text { multi-level when they are required } \\
\text { - Multi-team routines mainly used to } \\
\text { align on multi-team releases }\end{array}$ \\
\hline
\end{tabular}

bottom-up approach defined transparency on problems causing potential delays and the continuous improvement of internal workflows as the key agile principles. Hence, our case study shows that a relationship between the identified principles and implementation objectives exists, as the defined principles support the defined implementation objectives of the two different approaches.

When implementing organizational structures, those companies following a top-down approach focus on establishing multi-team structures by introducing product-orientation on the vertical and a professional or technical focus on the horizontal axis. In contrast, companies following a bottom-up approach focus on team structure and configuration aiming at creating agile teams with a homogenous set of experienced employees with a broad variety of skills breaching the division of business and IT. Companies following a top-down approach also focus on building homogenous teams but implement multi-team structures first.

Related to agile roles, similar relations can be observed between companies following a top-down or bottom-up approach. Whereas those companies following a top-down approach, focus on implementing roles on multi-team level according to the product structure, companies following a bottom-up approach start to set roles on team level. Moreover, when scaling agile from the bottom-up, further roles are introduced that support the coordination of releases to obtain delivery speed when scaling to multiple teams. However, some of those additional roles also have product or product feature responsibility. Establishing those additional roles bottom-up bears the danger of integrating traditional management structures into the 
agile organization that are in conflict with agile principles.

The relation between the followed approach and the implementation is also true for the implementation of agile routines. Whereas case companies following a bottom-up approach are mainly focusing on implementing routines for team alignment, top-down case companies aim to foster product management alignment by establishing agile routines. Companies following a bottom-approach primarily focus on multiteam routines to coordinate releases. Case-companies following a top-down approach especially use multiteam alignment sessions for product planning. These meetings allow both case companies (CarCo, FinCo) to generate transparency on the product strategy and how every single task is contributing to achieving it. However, the alignment with top-management still takes place in the traditional way also for case companies following a top-down approach.

Our results do not show a relationship between a selected tool type and the followed implementation approach which is why the technology variable is not further discussed.

As outlined, our results show a relationship between the followed implementation approach and subsequent design of the implementation parameters as well as the social and technical work system. However, we observed that the assignment of a case company to either a top-down or bottom-up becomes more transparent with time spent on the implementation of scaled-agile frameworks. The case companies implemented scaledagile frameworks within a timeframe between less than one year (AirCo, RealCo) and over three years (FinCo).

\section{Conclusion}

As the business environment has become hypercompetitive in times of digital transformation and disruption, agility is changing from a domain-specific phenomenon to a corporate mode of working [14]. Consequently, scaled-agile frameworks have drawn increased attention as means to increase speed and flexibility. While extant research primarily examines the implementation implications of agile structures at non-digital born enterprises $[5,9,10]$, our exploratory multiple case investigates the design choices in the implementation of scaled-agile frameworks beyond IT and scaled-agile framework agnostic. We found that companies implementing scaled-agile frameworks either follow a top-down or bottom-up approach based on different objectives followed by the implementation.
Hence, both approaches result in a different design of the work system to best support the selected objectives.

We contribute to the development of the STS theory by adding on the parameters that define a work system design, especially in the context of scaled-agile frameworks implementations. Thus, we highlight a change in the paradigm that is at heart of STS theory, namely the sequential implementation approach where an extensive design phase (phase 1 and 2) is then followed by the implementation phase (phase 3) [6]. Rather, we observed that contemporary work system implementation favors an iterative approach where design and implementation activities alternate continuously. This incremental design and implementation approach allows adjustments to the initial design based on gathered feedback.

We observed several management decisions that may help companies in their own efforts to implement scaled-agile frameworks. The case study focused on the reduction of hierarchical levels and the increase of customer centricity followed a top-down approach, whereas companies that focused on increasing delivery speed and shortening time to market followed a bottomup approach. Depending on the identified objective of a company, managers can design their scaled-agile framework according to our observation made among our case companies. Moreover, we offer companies adopting scaled-agile practices further recommendations for the implementation and work system design. As a caveat we observed among our case companies that most transformation initiatives have not really reached the top management layer yet, which may represent a major inhibitor for implementation success [30].

Our study does not come without limitations: We have identified six cases to be representative for an implementation of a scaled-agile framework in nondigital born enterprises. However, the cases might not be fully representative for companies of all industries and size classes. Moreover, most case companies are at an early level of the implementation of scaled-agile frameworks, except for FinCo. But, as we aimed for a deeper understanding for patterns of scaled-agile framework implementation, generalizability was not our goal. Finally, the multiple case study relies on a small number of total interviews (18 interviews in total) which are not equally distributed among the case companies which could lead to unbalanced results and biases.

Hence, future research should focus on the following aspects: First, to understand more about different objectives which are followed and the implications on the implementation and work system design especially with case companies at an more mature stage of scaled- 
agile implementation. Second, it should be investigated if the identified objectives for the implementation are interrelated or have means-end relationships. Third, further research should investigate whether the identified patterns of implementation approaches become more salient over time when companies are at a later stage of implementation.

Despite the profound change which is induced by the implementation of scaled-agile framework, starting a company's agile tranformation is crucial for succeeding in a business environment of high uncertainty and the company's digital transformation.

\section{References}

[1] C. Matt, T. Hess, and A. Benlian, "Digital Transformation Strategies", Business \& Information Systems Engineering (57:5), 2015, pp. 339-343.

[2] D. J. Teece, M. Peteraf, and S. Leih, "Dynamic Capabilities and Organizational Agility: Risk, Uncertainty, and Strategy in the Innovation Economy", California Management Review (58:4), 2016, pp. 13-35.

[3] D. Gerster, C. Dremel, and P. Kelker, "Agile Meets NonAgile: Implications of Adopting Agile Practices at Enterprises", Proceedings of the Twenty-fourth Americas Conference on Information Systems, 2018, pp. 1-10.

[4] T. Karvonen, H. Sharp, and L. Barroca, "Enterprise Agility: Why Is Transformation so Hard?", International Conference on Agile Software Development, 2018, pp. 131145

[5] R. P. Bostrom, and J. S., Heinen, "MIS Problems and Failures: A Socio-Technical Perspective, part I", MIS Quarterly (1:3), 1977, pp. 17-32.

[6] R. P. Bostrom, and J. S. Heinen, "MIS Problems and Failures: A Socio-Technical Perspective, part II: the application of socio-technical theory", MIS Quarterly (1:4), 1977, pp. 11-28.

[7] I. Haffke, B. Kalgovas, and A. Benlian, "Options for Transforming the IT Function Using Bimodal IT," MIS Quarterly Executive (16:2), 2017, pp. 101-120.

[8] M. Kalenda, P. Hyna, and B. Rossi, "Scaling agile in large organizations: Practices, challenges, and success factors", Journal of Software: Evolution and Process (30), 2018, e1954. [9] D. Gerster, C. Dremel, W. Brenner, and P. Kelker, "How Enterprises Adopt Agile Structures: A Multiple-Case Study", Proceedings of the 52nd Hawaiian Conference on Systems Science (HICSS), Maui, HI, USA, 2019, pp. 4957-4966.

[10] S. Tumbas, N. Berente, S. Seidel, and J. vom Brocke, "The 'Digital Façade' of Rapidly Growing Entrepreneurial Organization", Proceedings of the Thirty Sixth International Conference on Information Systems, 2015, pp. 1-19.

[11] K. Conboy, and B. Fitzgerald, "Toward a conceptual framework of agile methods: a study of agility in different disciplines", Proceedings of the 2004 ACM workshop on Interdisciplinary software engineering research, 2004, pp. 37 44.
[12] T. Burgess, "Making the Leap to Agility: Defining and Achieving Agile Manufacturing through Business Process Redesign and Business Network Redesign", International Journal of Operations and Production Management (14:11), 1994, pp 23-34.

[13] M. Fowler, and J. A. Highsmith, "The Agile Manifesto", Software Development (9:8), 2001, pp. 28-35.

[14] E. Overby., A. Bharadwaj, and V. Sambamurthy, "Enterprise agility and the enabling role of information technology", European Journal of Information Systems (15:2), 2006, pp. 120-131.

[15] M. Laanti, "Characteristics and Principles of Scaled Agile", International Conference on Agile Software Development, 2014, pp. 9-20.

[16] K. Beck, "Embracing Change with Extreme Programming”, Computer (32:10), 1999, pp. 70-77.

[17] Poppendieck, M., and Poppendieck, T., "Lean Software Development", Sage, USA, 2001.

[18] Beedle, M., and Schwaber, K., "Agile Software Development with Scrum”, Sage, USA, 2001.

[19] K. Conboy, "Agility from first principles: Reconstructing the concept of agility in information systems development", Information Systems Research (20:3), 2009, pp. 329-354.

[20] Kniberg, H., and Anders, I., 2012, "Scaling Agile @ Spotify with Tribes, Squads, Chapters \& Guilds." from https://blog.crisp.se/wpcontent/uploads/2012/11/SpotifyScali ng.pdf

[21] K. Dikert, M. Paasivaara, and C. Lassenius, „Challenges and success factors for large-scale agile transformations: A systematic literature review", The Journal of Systems and Software (119), 2016, pp. 87-108.

[22] H. J. Leavitt, “Applied organization change in industry: Structural, technical, and human approaches; new perspectives in organizational research", J. G (ed.) Handbook of Organizations, Chicago, Rand McNally, 1965, pp. 55-71.

[23] C. W. Clegg, P. Waterson, and N. Carey, "Computersupported collaborative working - lessons from elsewhere", Journal of Information Technology (9:2), 1994, pp. 85-98.

[24] W. J. Kettinger, J. T. C. Teng, and G. Subashish, "Business process change: A study of methodologies, techniques, and tools", MIS Quarterly (21:1), 1997, pp. 55-80. [25] K. Lyytinen, and L. Mathiassen, "Attention shaping and software risk - A categorical analysis of four classical risk management approaches", Information Systems Research (9:3), 1998, pp. 233-255.

[26] Creswell, J.W., Qualitative inquiry and research design, Sage, USA, 2013.

[27] I. Etikan, S.A. Musa, and R.S. Alkassim, "Comparison of convenience sampling and purposive sampling", American Journal of Theoretical and Applied Statistics (5:1), 2016, pp. $1-4$.

[28] McCracken, G., The long interview, Sage, Canada, 1988. [29] Strauss, A., and Corbin, J. M., Basics of qualitative research: Grounded theory procedures and techniques, Sage, USA, 1990.

[30] A. Benlian, and I. Haffke, "Does Mutuality Matter? Examining the Bilateral Nature and Effects of CEO-CIO Mutual Understanding", The Journal of Strategic Information Systems (25:2), 2016, pp. 104-126. 